\title{
Hegemoni Kolonialisme Terhadap Kekuasaan di Nusantara: Strategi Politik Daendels Meruntuhkan Kesultanan Banten Tahun 1808-1811
}

\author{
Faizal Arifin \\ Sekolah Tinggi Ilmu Adab dan Budaya Islam Riyadul 'Ulum \\ Corresponding author's e-mail: faizalarifin@stiabiru.ac.id
}

\begin{abstract}
This article discusses Herman Willem Daendels' political policies on the collapse of the political power period of the Sultanate of Banten. This study is interesting because Banten has the geopolitical potential to endanger Batavia and also economic potential, which motivated Daendels to destroy it in a short time, paralyzed the traditional ruler (Sultanate) of Banten which had stood for several centuries. The historical method with the political approach is used to examine and analyze various historical records of Daendels' strategy and political implementation which makes use of the situation of the weakening power of the Sultanate of Banten. The research results indicated that through various political events including the refusal of the Sultan to surrender the Palace and the killing of Dutch envoys, gives Daendels gained legitimacy to disarm Banten's rule until it was abolished and did not have sovereignty. Although the Sultanate's political institutions were abolished, the hope of the return of the "Sultan of Banten" incessantly and the Islamization of culture remained rooted in the people of Banten.
\end{abstract}

Keywords: Banten, Daendels, Colonialism, Local History

Abstrak: Penelitian ini menganalisis berbagai kebijakan politik praktis Herman Willem Daendels kepada Kesultanan Banten saat periode lemahnya kekuasaan politik Banten. Peristiwa ini menarik untuk diteliti karena sebagai wilayah yang secara geopolitik berpotensi membahayakan Batavia serta memiliki potensi ekonomi, yang menjadi motivasi politik Daendels dalam kekuasaannya yang singkat turut serta melumpuhkan penguasa tradisional (kesultanan) Banten yang telah berdiri beberapa abad. Metode sejarah dengan pendekatan sejarah politik digunakan untuk menelaah dan menganalisa berbagai catatan historis mengenai strategi serta implementasi politik Daendels yang memanfaatkan dengan cermat situasi melemahnya kekuasaan Kesultanan Banten. Hasil penelitian menunjukkan berbagai peristiwa politik diantaranya penolakan Sultan menyerahkan Keraton dan terbunuhnya utusan Belanda, Daendels mendapatkan legitimasi untuk melucuti kekuasaan Banten hingga dihapuskan dan tidak memiliki kedaulatan. Meskipun secara institusi politik Kesultanan sudah dihapuskan namun harapan kembalinya "Sultan Banten" tidak berhenti dan Islamisasi budaya tetap mengakar pada masyarakat Banten.

Kata kunci: Banten, Daendels, Kolonialisme, Sejarah Lokal

\section{Pendahuluan}

Runtuhnya kekuasaan Banten di Jawa, merupakan awal dari intervensi politik Belanda pada Kesultanan di Nusantara, pasca dibubarkannya Vereenigde Oostindische Compagnie (VOC), perusahaan kongsi dagang internasional Belanda di Hindia Timur pada akhir abad 20. Sebelumnya, intervensi dan intrik politik dilakukan Kompeni VOC terhadap kekuasaan tradisional di Nusantara selama beberapa puluh tahun. Bukan hanya melalui diplomasi dan tekanan politik, VOC juga menggunakan kekerasan bersenjata bagi kesultanan atau kerajaan yang menentang dan menjadi oposisi. Setelah VOC dibubarkan karena korupsi dan penyelewengan kekuasaan, politik ekspansi dan intervensi tetap dilanjutkan oleh 
Pemerintah Kolonial Belanda di Nusantara. Diantara utusan Pemerintah Kolonial Belanda adalah diangkatnya Gubernur Jenderal Daendels. Daendels menjadi tokoh pertama yang melakukan reformasi politik pada wilayah Banten yang dilatarbelakangi oleh situasi politik dan ekonomi (Wijono, 2017). Selain Banten, dalam periode kekuasaan yang terbatas, Daendels melakukan berbagai perubahan diantaranya reformasi ekonomi terhadap daerahdaerah lain misalnya Palembang dan Pulau Bangka (Sya et al., 2019). Daendels bahkan melakukan reformasi demografis misalnya dengan menghapuskan golongan Kalang dalam kategorisasi kependudukan bumiputera (Warto, 2011).

Dalam proses-proses perubahan tersebut, terdapat berbagai pertentangan dan peristiwa politik seperti penentangan Kesultanan Banten terhadap Daendels. Dalam penulisan sejarah, terdapat perbedaan perspektif mengenai kedatangan Belanda di Nusantara. Bagi Belanda, kehadiran mereka di Nusantara ditujukan untuk kepentingan ekonomi yaitu berdagang komoditas yang menguntungkan di pasar Eropa. Bahkan VOC dianggap sebagai "pemersatu" (Kartodirdjo, 1987) dan kedatangan Belanda ke benua lain dianggap sebagai penyebaran Eropa bagi kemajuan dunia (Universitas Gadjah Mada, 1958). Sebaliknya bagi bangsa Indonesia, kedatangan Belanda yang berawal dari kerjasama perdagangan berubah menjadi monopoli yang dipaksakan sepihak serta penjajahan yang didukung kekuatan militer. Perspektif kolonial dalam menuliskan sejarah yang disebut Neerlando-sentrisme menjadikan kepentingan dan pendapat Belanda sebagai pijakan dan pedoman penulisan (Ali, 2012).

Oleh karena itu diperlukan penulisan sejarah dalam perspektif Indonesia-sentris yang menampilkan peran dan bangsa Indonesia sebagai bentuk dekolonisasi yang melepaskan diri dari pengaruh penjajahan dalam historiografi (Mulyana \& Darmiasti, 2009). Setidaknya bagi Kuntowijoyo, historiografi Indonesiacentrisme bermula sejak tahun 1957 yang disebut era "kesadaran sejarah baru" (Kuntowijoyo, 2003). Penulisan sejarah Banten sebagai kekuatan besar di Nusantara yang berdiri sejak abad 16, menarik untuk dikaji karena berbagai nilai seperti keberanian, heroisme, pantang menyerah sampai kekuatan terakhir, sikap melindungi rakyat, kehati-hatian mengambil keputusan, serta bertahan dari intervensi asing yang didapatkan pada jejak historis berupa catatan sejarah ataupun sumber sejarah monumental, dapat menjadi pelajaran bagi kedaulatan bangsa serta strategi menghadapi dominasi dan intervensi bangsa asing. Unsur politik menjadi pembahasan penting oleh karena itu artikel ini termasuk dalam kajian sejarah politik (Kuntowijoyo, 2003). Fokus penelitian pada masa kekuasaan Daendels pada abad 19, ditujukan untuk membahas peristiwa-peristiwa yang melatarbelakangi runtuhnya Kesultanan Banten karena penelitian Claude Guillot, sejarawan Perancis, membatasi penelitiannya tentang sejarah Banten sampai 
abad XVII (Guillot, 2011). Penjelasan kronologis pada detik-detik runtuhnya kekuasaan Kesultanan Banten juga tidak banyak dijelaskan dalam tinjauan kritis sejarah Banten karya Hoesein Djajadiningrat (Djajadiningrat, 1983). Penulisan sejarah pada artikel ini membahas hubungan Daendels dengan Kesultanan Banten dalam perspektif Indonesia-sentris, yang membahas dua topik utama yaitu pertama, bagaimana strategi politik yang dilakukan Daendels dalam mengintervensi bahkan menghapuskan kekuasaan Kesultanan Banten yang sebelumnya berdaulat; kedua, faktor internal melemahnya kekuasaan Banten. Penelitian ini dapat memberikan penjelasan (eksplanasi) mengenai bagaimana peristiwa runtuhnya kesultanan Banten serta urgensi membangun kekuatan militer dan teknologi bagi kedaulatan bangsa sebagai bagian tidak terpisahkan bagi para penguasa politik di berbagai zaman.

\section{Metode}

Metode penelitian yang dilakukan adalah metode sejarah karena objek penelitian adalah peristiwa-peristiwa yang terjadi di masa lalu. Masa lampau termanifestasi melalui dokumentasi akan realitas pada masanya yang terdapat pada sumber arsip serta dokumen sejarah. Oleh karena itu, terdapat patokan dan prosedur khusus yang harus dilakukan di dalam penelitian yang berhubungan dengan sejarah yaitu metode penelitian sejarah atau metode historis (Sjamsuddin, 2012). Daliman memaparkan empat prosedur metode sejarah yaitu heuristik, kritik (verifikasi), interpretasi, dan historiografi (Daliman, 2012). Heuristik merupakan langkah pertama yaitu kegiatan mencari sumber-sumber sejarah dengan tujuan mendapatkan data-data, materi sejarah atau evidensi sejarah (Sjamsuddin, 2012).

Beberapa sumber primer yang digunakan diantaranya adalah laporan pertanggungjawaban kekuasaan yang ditulis oleh Daendels yaitu Staat der Nederlandsche Oostindische bezittingen (1814) serta berbagai arsip berbahasa Belanda lainnya dimana terdapat konten yang relevan dengan peristiwa runtuhnya Banten diantaranya Woordenboek van de vaderlandse geschiedenis met inbegrip van België, Oost- en West-Indië, Zuid-Afrika en de voormalige Nederlandse koloniën; Overzicht van de geschiedenis onzer koloniën; Tijdschrift voor Neerland's Indië jrg 2, 1864; Bijdragen tot de taal-, land- en volkenkunde van Nederlandsch-Indië, 1867; Handleiding tot de kennis der nieuwe geschiedenis, voor de kadetten van alle wapenen; serta dokumen sejarah lain yang relevan mulai dari sumber kolonial sampai penelitian sejarah terkini. Tahap selanjutnya setelah heuristik adalah kritik. Kritik yaitu verifikasi terhadap sumber-sumber sejarah yang digunakan, baik kritik eksternal maupun internal. Kritik eksternal yang dilakukan yaitu memverifikasi otentisitas sumber primer terutama laporan Daendels yang dipublikasikan tahun 1814 setelah meninggalkan Hindia Belanda, dengan judul Staat der Nederlandsche Oostindische bezittingen (1814). 
Dokumen tersebut diverifikasi dengan daftar beberapa koleksi dokumen diantaranya koleksi di National Library of Australia (Staat der Nederlandsche Oostindische bezittengen, onder het bestuur van den gouverneur-generaal Herm... / National Library of Australia, n.d.) serta koleksi salah satu museum besar di Belanda yaitu Rijksmuseum (Staat der Nederlandsche Oostindische Bezittingen, onder het bestuur van den Gouverneur-Generaal Herman Willem Daendels (....) in de jaren 1808 - 1811, Hendrik van Teecklenburgh, 1814 - Rijksmuseum, n.d.). Dokumen Daendels dari tahun 1814 tersebut juga digunakan oleh Peter Carey dalam salah satu artikel yang membahas sejarah Jawa berjudul The Power of Prophecy: Prince Dipanagara and the End of an Old Order in Java, 1785-1855 (Carey, 2007). Laporan Kolonial dari Gubernur Jenderal Daendels ini juga terdapat sebagai salah satu referensi sumber sejarah dalam buku De eerste publicatien over koloniale economie na Nederlands herstel in 1813 yang ditulis oleh Kemp (Pieter Hendrik van der Kemp, 1915, p. 306).

Beberapa konfirmasi tersebut menyimpulkan bahwa dokumen adalah autentik dan layak digunakan sebagai sumber primer dalam penelitian ini. Kritik internal dari sumber yang autentik memverifikasi kompeten atau tidaknya sumber sejarah serta menggunakan koroborasi yang ditujukan kepada fakta-fakta sejarah yang muncul untuk diverifikasi kebenarannya (Herlina, 2020, pp. 52-57). Peneliti melakukan kritik internal dengan membandingkan laporan Daendels yang sarat kepentingan kolonial dengan catatan Belanda lainnya, penelitian terbaru di artikel ilmiah, serta beberapa buku referensi. Hasilnya, berbagai catatan kritis terdapat dalam penulisan penelitian ini. Interpretasi yang dipilih oleh peneliti adalah penafsiran (teori) orang besar karena melibatkan peran penting para elit politik dalam perkembangan sejarah (Sjamsuddin, 2012, p. 131). Pembahasan pergesekan kedua struktur kekuasaan yaitu Sultan Banten dan Gubernur Jenderal Daendels menjadi penyebab utama dan fokus pembahasan penelitian tentang runtuhnya Kesultanan Banten. Fakta yang didapatkan, melalui proses analisis dan sintesis, dengan mempertimbangkan pendekatan politik. Pada tahapan historiografi mengelaborasi antara penafsiran, penjelasan (eksplanasi) dan penyajian secara sistematis (Sjamsuddin, 2012). Proses historiografi dilakukan dengan menyeleksi fakta-fakta, serta berusaha menghilangkan bias, menggunakan imajinasi untuk memperoleh kaitan dan mata rantai yang menghubungkan berbagai peristiwa serta menyusun berbagai fakta dan peristiwa di Banten dalam aspek kronologi.

\section{Hasil Dan Pembahasan}

\section{Gubernur Jenderal Pertama Hindia Belanda}

Pasca VOC dibubarkan 31 Desember 1799, kekuasaannya diambil alih oleh Pemerintah Kerajaan Belanda dengan membentuk Hindia Belanda di Nusantara. Gubernur 
Jenderal pertama yang diangkat yaitu Herman Willem Daendels (1762 - 1818), seorang politikus yang dipilih Belanda untuk memerintah Hindia Belanda pada 1808-1811. Djoko Marihandono menyatakan bahwa berdasarkan buku-buku sejarah (diantaranya buku Soekanto, Vlekke, dan Polak), Gubernur Jenderal Daendels dikenal sebagai seorang diktator yang sangat kejam, tidak berperikemanusiaan, dan selalu menindas rakyat demi keuntungan pemerintah Kolonial Belanda dan pribadinya (Marihandono, 2003).

Daendels dipilih menjadi penguasa di Hindia Belanda, setelah beberapa tahun sebelumnya ia berpihak pada Perancis yang tengah merevolusi Kerajaan-Kerajaan Eropa dengan paham demokrasi. Sebelumnya, ia merupakan salah satu dari ribuan orang Belanda yang diusir oleh gerakan kontra-revolusi yang dikontrol Prusia (Vlekke, 2008). Daendels memimpin militer Legiun Batavia (Batavian Legion) yang memihak Perancis serta menentang kekuasaan para Raja dan bangsawan (Klerck, 1938). Bersama legiunnya, ia berhasil menaklukan Belanda Selatan tahun 1794, setelah sebelumnya Perancis mendeklarasikan perang terhadap Tujuh Provinsi (Zeven Provinciën) Belanda. William V yang sudah terpojok meminta bantuan Inggris dan menaiki kapalnya. Pada 18 Januari 1795, saat William V masih di sana, pasukan Perancis berhasil memasuki Den Haag dan dalam beberapa jam Amsterdam dikuasai dan berdirilah Republik Batavia.

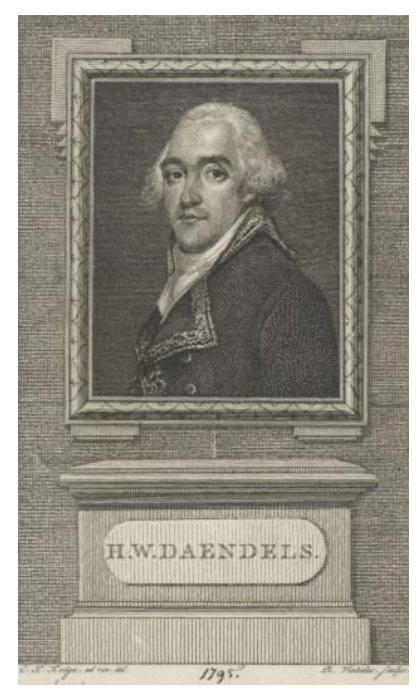

\section{Gambar 1: Daendels tahun 1795}

(Portret van Hendrik Willem Daendels, karya Reinier Vinkeles dan Charles Howard Hodges tahun 1795, Collectie Rijksmuseum)

Daendels menerima dua tugas utama dari Louis Napoléon Bonaparte (1778-1846), adik dari Napoleon Bonaparte, Kaisar Perancis. Louis mendapatkan julukan King Louis I of Holland, karena menjadi raja di negeri Belanda sesaat setelah Perancis menguasai Belanda. Dua tugas utama diberikan pada Daendels, sebelum ia berangkat ke Jawa dari Belanda. Tugas pertama mempertahankan Pulau Jawa agar tidak jatuh dan ditaklukan Inggris. Hal ini 
merupakan turunan dari konflik yang sedang berlangsung di Eropa yaitu Perang Napoleon. Pada perang tersebut Perancis telah berhasil menguasai banyak wilayah di Eropa Kontinental (termasuk Belanda) dan Inggris merupakan musuh utama paling kuat dalam koalisi kerajaan-kerajaan Eropa yang menentang Perancis. Adapun tugas kedua, adalah melakukan perbaikan sistem administrasi negara jajahan di Jawa. Hal tersebut penting dilakukan mengingat evaluasi atas hancurnya VOC dikarenakan manajerial organisasi yang korup dan kacau sehingga perlu perombakan radikal.

Daendels menerima penugasannya pada 28 Januari 1807 dari Louis Napoleon atas restu Napoleon, Kaisar Perancis. Selama satu bulan lebih, Daendels dengan segera menyiapkan perbekalan dan semua yang diperlukan untuk perjalanannya ke Jawa. Pada 9 Februari 1807, sebelum berangkat, Daendels menerima 37 pasal yang merupakan titah dari Louis Napoleon ketika ia menjadi Gubernur Jenderal di Jawa. Bulan Maret Daendels berangkat dengan sembunyi-sembunyi agar tidak diketahui Inggris karena perang masih berkecamuk. Bukan hanya itu, ia bahkan mengganti nama menjadi Van Vlierden, dan menggunakan rute perjalanan yang tidak lazim. Ia pergi melalui Paris ke Lisabon menaiki kapal Amerika, kemudian ke Kepulauan Kanari dan selanjutnya ke Jawa (Marihandono, 2003).

Setelah 10 bulan dalam perjalanan rahasia, Daendels mendarat di Anyer pada tanggal 1 Januari 1808 dengan hanya didampingi oleh seorang ajudan. Demi alasan keamanan serta mengantisipasi jika diperiksa Inggris di tengah perjalanan, Daendels dan ajudannya tidak membawa surat-surat penting terkait dokumen pengangkatan Gubernur Jenderal. Dengan menempuh jalan darat, Daendels menuju gubernur jenderal yang sedang berkuasa saat itu, Henricus Albertus Wiese. Setelah dua pekan, Wiese menerima berita pengangkatan Daendels dan menyerahkan kekuasaannya tanggal 14 Januari 1808. Dalam mempertahankan Jawa dari serangan Inggris atau pihak lain, Daendels memiliki pasukan dengan kekuatan 20.000 orang serta angkatan laut (Duinen, 1918). Menurut Ricklefs, Daendels karena tidak membawa pasukan, ia meningkatkan jumlah pasukan dengan cukup signifikan dimana sebelumnya berjumlah 4.000 saja menjadi 18.000 serdadu (Ricklefs, 2008).

\section{Hubungan Banten dengan Daendels}

Banten merupakan wilayah yang diakui Daendels sebagai tapal batas sebelah Barat wilayah Hindia Timur yang dikuasai Belanda. Hindia Timur (Oost Indie) diantaranya meliputi wilayah Jawa yaitu Batavia, Kesultanan Cirebon, Pantai Timur Jawa (Noord-Oostkust) dan Wilayah Ujung Timur Jawa (Marihandono, 2011). Selain Banten, wilayah lain yang dianggap tidak berada di bawah Belanda adalah tapal batas selatan yaitu Vorstenlanden, Kesultanan 
Yogyakarta dan Surakarta. Dalam kepungan dua kekuasaan pribumi yang berdaulat di batas Barat dan batas Selatan, Daendels dengan strategi politiknya pernah menurunkan Sultan Hamengkubuwono II di Yogyakarta dengan 3.200 serdadu dan merampas 500.000 gulden (Ricklefs, 2008). Di tapal batas Barat yang dekat dengan Batavia, Kesultanan Banten mengalami peristiwa serupa dengan kepungan 1.000 serdadu yang secara rinci dan kronologis akan dijelaskan pada bagian selanjutnya. Hubungan antara Daendels dan Sultan Banten dimulai dari rencana pembangunan De Grote Postweg, jalan raya Anyer-Panarukan serta pelabuhan perang (militer) di Selat Sunda, Ujung Kulon.

Mega-proyek tersebut direncanakan dapat memotong jalur perjalanan dari Anyer ke Panarukan sebelumnya lebih dari satu bulan menjadi delapan hari. Ribuan pekerja telah dikerahkan untuk membuat jalan dan pelabuhan tersebut. Proyek infrastruktur ini telah menelan banyak korban nyawa termasuk dari kalangan bumiputera bahkan Eropa. Velderhof bahkan menyebut tengah-tengah rawa ini sebagai "Kuburan Belanda" (het graf de Hollanders), saking mengerikannya kematian yang diderita (Velderhof, 1901). Banyaknya korban disebabkan karena pelaksanaan proyek pada tanah rawa-rawa yang mengakibatkan timbul penyakit demam yang mematikan. Menurut Duinen, penyakit tersebut adalah malaria dan ribuan telah meninggal karenanya (Duinen, 1918). Kebulatan tekad Daendels untuk membangun Grote Postweg, terlihat pada lukisan karya Raden Saleh saat Daendels menunjuk dengan tangan kirinya pada peta mega-proyek.

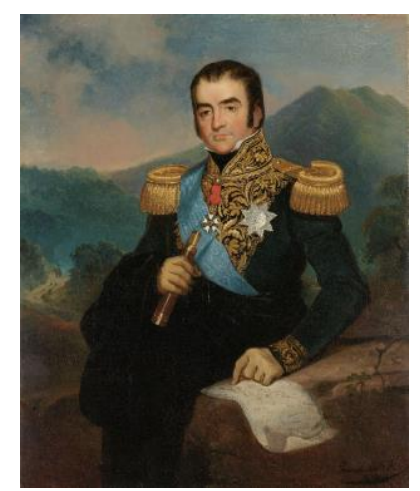

Gambar 2: Daendels sebagai Gubernur Jenderal Hindia Belanda (Posthumous Portrait of Herman Willem Daendels, Governor-General of the Dutch East Indies, karya Raden Saleh tahun 1838, Collectie Rijksmuseum)

Untuk melanjutkan proyek, Daendels mendesak kepada Sultan Banten untuk menyediakan pekerja baru. Sultan Banten menolak permintaan tersebut karena pertimbangan kemanusiaan dan kekhawatiran berbuat zalim terhadap rakyat. Sebelumnya, Kesultanan Banten telah mengerahkan 1.500 pekerja untuk proyek dan hampir semua meninggal dunia karena wabah malaria di rawa-rawa (Eijkman \& Stapel, 1924). Sultan kemudian mengirim dua utusan ke Batavia, di bawah koordinasi seorang komandan Belanda, 
untuk memberi informasi kepada Gubernur Jenderal Daendels bahwa tidak mungkin untuk mengumpulkan pekerja yang diperlukan (Duinen, 1918).



Gambar 3: Daendels dan Grote Postweg

(Daendels Legt De Groote Postweg Aan Over Java, ilustrasi diterbitkan tahun 1920, Collectie KITLV)

Daendels tidak bisa menerima alasan tersebut, kemudian mengirimkan kembali utusan bernama Komandan Du Puy untuk mendesak Sultan Banten agar segera memenuhi lima tuntutan sebelum 15 November 1808. Diantara kelima tuntutan adalah pertama, mengirim pejabat setingkat gubernur ke Batavia menghadap Daendels. Kedua, mengirimkan 1.000 orang per hari untuk pekerjaan pembangunan. Ketiga, Sultan meroboh-kan keratonnya dan pindah ke Anyer. Sedangkan tuntutan keempat dan kelima tidak terlalu penting (Verwey, 1905). Dengan syarat mengirimkan jumlah pekerja yang wajib disediakan Sultan adalah 1.000 orang per hari sebenarnya berat dilakukan (Laan, 1939). Selain itu intimidasi yang tidak masuk akal adalah persyaratan ketiga, Sultan didesak untuk menyerahkan Kesultanan Banten pada Belanda serta mengekstradisi dengan memindahkan kediamannya dari Banten ke Anyer (Duinen, 1918). Berbagai persyaratan yang tidak masuk akal untuk dilaksanakan. Tuntutan ini disampaikan langsung oleh Daendels kepada para utusan dari Kesultanan Banten. Oleh salah satu diantara mereka yang hadir, disampaikanlah persyaratan tersebut dalam bahasa Melayu. Para utusan mulai geram namun mereka berada di tempat musuh. Du Puy pun khawatir jika persoalan ini menimbulkan krisis.

Tiga hari sebelum ultimatum berakhir, Sultan memutuskan untuk menerima persyaratan pertama yaitu mengirim perwakilan setingkat gubernur serta mengusahakan tersedianya pekerja. Namun syarat dibubarkannya keraton ditolak dan tidak mungkin dilaksanakan. Selain itu, makam leluhur Kesultanan Banten berada di Keraton yang tidak mungkin ditinggalkan (Verwey, 1905). Jawaban itu segera direspon oleh Daendels dengan ancaman bahwa Sultan harus memenuhi semua tuntutan dan tidak terkecuali. 




Gambar 4: Masjid Agung dan Makam

Uavaansche tempel nabij Bantam Karya van de Velde dan P. Lauters, tahun 18 Collectie KITLV)

Pada sore hari tanggal 14 November, Du Puy pergi ke Keraton untuk menyampaikan jawaban Daendels. Ia datang bersama seorang letnan dan 14 serdadu (Verwey, 1905). Merasa direndahkan dan menodai kedaulatan Kesultanan Banten maka Du Puy diserang dan terbunuh beserta tentaranya pada hari tersebut. Sedangkan dalam catatan lain, tertulis tanggal 15 November 1808, Du Puy diserang oleh para pasukan pengawal Sultan (Bijdragen tot de taal-, land- en volkenkunde van Nederlandsch-Indië, 1867, 1867). Dalam catatan Daendels, disebutkan bahwa yang terbunuh selain Komandan Belanda Du Puy, adalah Letnan Infanteri Rohl, seorang tentara Eropa dan tiga tentara pribumi yang berpihak Belanda (Daendels, 1814).

Pada kesempatan penyampaian persyaratan desakan Belanda yang menjadi tugas para utusan Belanda, ditemukan informasi bahwa pembunuhannya terjadi di istana dan berada di bawah pengawasan sultan dan para pembantunya, serta tercatat bahwa penyerangan Du Puy atas perintah kepala pemerintahan setingkat gubernur (satu level di bawah Sultan) (Tijdschrift voor Neerland's Indië jrg 2, 1864 (1e deel), no 1 Deel-1e deel, 1864). Keadaan ini membuat Daendels marah, memberikan ia legitimasi untuk menyerang Banten. Daendels melakukan provokasi, menegosiasikan syarat yang tidak mungkin dapat dipenuhi lalu mengeluarkan senjatanya dengan dalih mengatasi gangguan publik atau huru-hara.

Sebenarnya keinginan Daendels untuk menguasai sepenuhnya wilayah Banten telah diinginkan tiga hari sebelum insiden tewasnya Du Puy. Keinginan tersebut tertera dalam surat Daendels yang ditulis pada 12 November 1808 dan ditujukan pada Menteri Jajahan (Tijdschrift voor Neerland's Indië jrg 2, 1864 (1e deel), no 1 Deel-1e deel, 1864). Daendels dalam surat tersebut, menyatakan bahwa daratan luas Ommelansden Batavia serta daerah-daerah subur di wilayah Banten, termasuk Tangerang, menawarkan kesempatan 
kepada Kolonial untuk memperluas budidaya pangan berupa padi. Selain motif ekonomi, penguasaan wilayah-wilayah ini memberikan keamanan bagi ibukota Kolonial yaitu Batavia dari segi geopolitik.

\section{Pengepungan dan Serangan Ofensif Daendels}

Dua hari setelah kematian Du Puy, Daendels sendiri yang langsung memimpin pasukan menuju Banten. Perjalanan dari Batavia ke Serang dan Banten ini memakan waktu kurang lebih 20 jam. Banten diserang dengan mengerahkan pasukan infanteri 1.000 orang beserta empat meriam yang diarahkan ke Keraton (Velderhof, 1901). Daendels melaporkan bahwa benteng Kesultanan dikepung selama tiga hari, dan dipertahankan oleh 3.000 pasukan, akhirnya jatuh ke tangan Belanda (Daendels, 1814).

Kesultanan Banten tidak sanggup menghadapi serangan tersebut. Sultan secara terpaksa menerima Daendels di singgasananya. Daendels menjabat tangan Sultan tetapi ia tidak melepaskannya. Daendels menarik Sultan dengan tangannya dari singgasana, duduk di atas kursi kebesaran Sultan Banten dan berkata dengan singkat, "Aku jadi Sultan!” (Sandick, 1893). Hikayat Mareskalek karya Syekh Abdullah bin Muhammad Abu Bakar (ditulis tahun 1813-1815) menyebutkan bahwa Daendels merupakan tipikal sering memperolok priyayi atau bangsawan, berkata kasar, kurang ajar serta sangat marah jika keinginan tidak dapat tercapai (Lombard, 2005a). Selanjutnya, Pangerang Warga Diradja, yang dianggap sebagai penggagas dan pelaksana penyerangan Du Puy, dibawa ke hadapan Komisi Militer Belanda (Daendels, 1814). Kepala Pejabat Kesultanan Banten tersebut dijatuhi hukuman mati oleh Belanda dengan cara ditembak dan tubuhnya dilemparkan ke laut untuk menebar teror menakuti rakyat maupun kalangan istana yang mencoba melawan Belanda (Eijkman \& Stapel, 1924).

Dalam kondisi tersebut, benda pusaka dan berharga Keraton Banten dijarah oleh pasukan Daendels. Daendels sendiri mencatat dengan rinci bahwa perhiasan, emas, perak, uang tunai, muatan-muatan yang belum dibongkar, dan barang apapun lainnya yang dianggap bernilai dan ditemukan di Keraton Banten, akan dibagikan kepada para pasukan dan semua yang terlibat dalam ekspedisi militer pengepungan Banten, dengan pengecualian enam keris yang dianggap berharga, akan dikirimkan ke ruang kas perbendaharaan besar di Batavia (Daendels, 1814).Tidak heran jika istana Daendels merupakan bangunan yang mewah dan besar. Berikut beberapa gambar istana Daendels di Batavia dengan patung J. P. Coen di bagian depan halaman yang luas. 


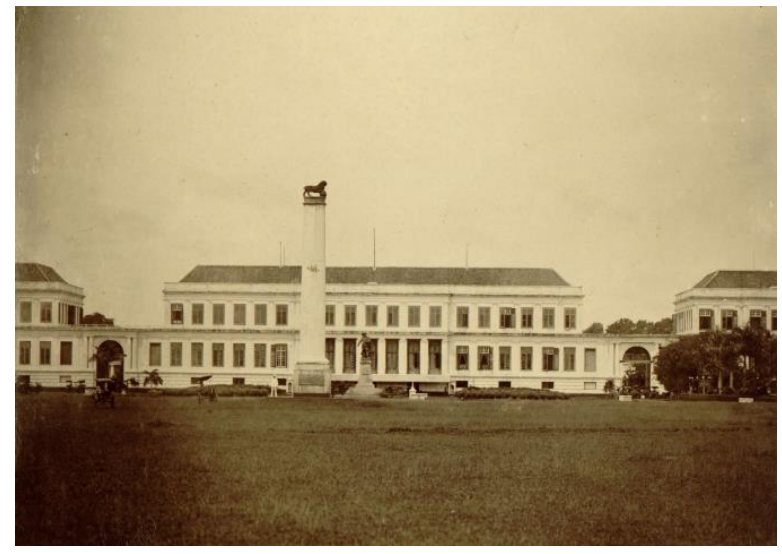

Gambar 5: Istana Daendels di Batavia

(KITLV A93 - Paleis van Daendels aan het Waterlooplein te Batavia, Collectie KITLV)

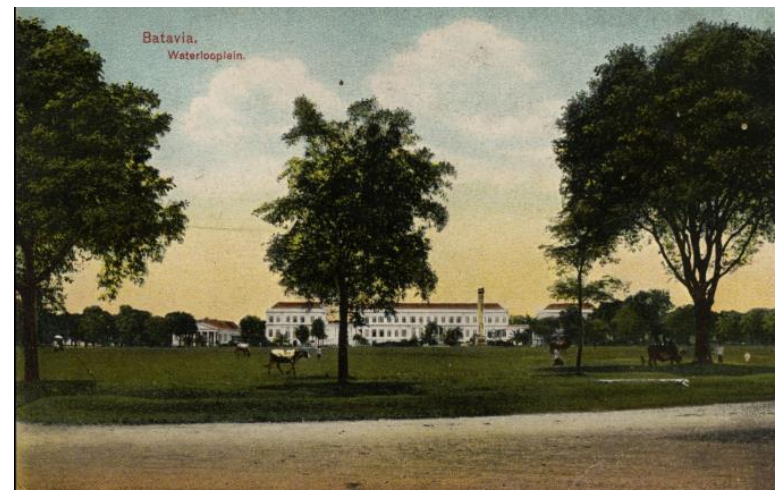

Gambar 6: Istana Daendels di Batavia

(Paleis van Daendels aan het Waterlooplein te Batavia, Collectie KITLV)

Nicolas Engelhard, dalam "survey" yang diterbitkan tahun 1816 menyebutkan bahwa perilaku Daendels di Keraton Banten sekejam perilaku Alexander Agung kepada Darius tahun 333 M (Verwey, 1905). Karena selain merampas harta, ia juga tidak menjaga kehormatan ibu, para istri, anak-anak dan istri sultan. Sultan Banten ditangkap dan diasingkan ke Ambon, setelah itu Kesultanan Banten dinyatakan sebagai wilayah kekuasaan raja Belanda keesokan harinya. Setelah peristiwa itu, sebagian besar Banten berada di bawah pemerintahan langsung Belanda. Tepatnya pada 22 November 1808, dalam catatan Daendels disebutkan bahwa Kesultanan Banten dideklarasikan menjadi wilayah kekuasaan Belanda, termasuk Lampung di Sumatra, yang sebelumnya diserahkan pada Sultan Banten tahun 1752 pada VOC (Daendels, 1814). Wilayah yang diklaim oleh Belanda termasuk wilayah Timur Banten, Tangerang, Cimandiri, Sading, Jasinga sampai wilayah di Batavia Ommenlanden. Dengan hasil perjanjian ini, keinginan Daendels yang sempat ia tujukan pada Menteri Jajahan pada 12 November 1808 terlaksana. Kematian Du Puy yang mendesak Sultan Banten dengan persyaratan yang tidak masuk akal, merupakan agenda yang direncanakan Daendels untuk melegitimasi tindakannya merebut wilayah-wilayah kekuasaan Banten. 


\section{Sultan Baru Tanpa Kekuasaan}

Daendels kemudian menunjuk seorang Sultan baru yaitu putra mahkota bernama Pangerang Ratoe Alioedien (P.H. van der Kemp, 1920) atau dalam dokumen lain disebutkan Pangerang Ratoe Mochamad Alie Oedien (Tijdschrift voor Neerland's Indië jrg 2, 1864 (1e deel), no 1 Deel-1e deel, 1864), yang sebenarnya diposisikan untuk sangat bergantung dan tunduk pada Belanda. Sultan dipaksa untuk tunduk pada perjanjian yang menyatakan bahwa semua keputusan pemerintahan akan berada di bawah komando Pemerintah Belanda tanpa Sultan dapat campur tangan atau memberikan perintah di dalamnya. Dokumen ini tertanggal 27 November 1808 dengan nama arsip Staat der Nederlandsche O. I. bezittingen, onder het bestuur van den Gouverneur Generaal Daendels, in het tweede stuk der bijlagen O. S. No. 4 (P.H. van der Kemp, 1920). Disebutkan bahwa Putra Mahkota Pangerang Ratoe Aliadien, di bawah kekuasan kolonial, diberi otoritas yang melebihi Bupati Bumiputera namun tidak sekuat Sultan. Tindakan-tindakan ini menunjukkan Daendels melakukan intervensi dan tindakan sesuka hati terhadap penguasa tradisional.

Selain melalui intimidasi kekuasaan dan teror, Daendels memaksakan budaya baru dalam kehidupan istana dengan menerbitkan aturan baru tentang "etika dan upacara" tahun 1808, yang dirasakan merendahkan martabat dan keagungan Kesultanan Banten sehingga perlawanan dari beberapa pihak di keluarga Sultan masih tertanam dan tidak berhenti. Aturan baru tersebut juga terjadi pada Kesultanan Yogyakarta dan Surakarta dimana posisi dan martabat raja direndahkan karena Residen dianggap setara dengan Sultan atau Raja (Poesponegoro \& Notosusanto, 2010). Selain dilatarbelakangi oleh ambisi politik, tindakan dan karakter Daendels lahir dari pemikirannya yang dipengaruhi Revolusi Perancis sehingga ia merupakan pembaharu yang revolusioner, anti-feodalisme dan penentang "despotisme" sekaligus otoriter sehingga banyak menuai perlawanan dan kebencian dari para penguasa di Nusantara yang terganggu (Ricklefs, 2005). Tidak heran, Vlekke, menjuluki Daendels sebagai "seorang Bonaparte" karena revolusioner sekaligus otoriter (Vlekke, 2008).

Menurut A.A. van Heusden, selain melakukan reformasi birokrasi, Daendels memang terkenal menjauhkan jarak antara para Sultan dengan Belanda karena pemerintahannya yang tiran, tidak menghormati hukum serta adat istiadat, memberikan hukuman sewenang-wenang dan kejam (Heusden, 1863, pp. 426-427). Tidak mengherankan jika masih di tahun yang sama yaitu 1808, terdapat tokoh yang melakukan perlawanan kepada Sultan Banten yang ditunjuk Daendels. Namanya adalah Ahmed dimana ia sebelumnya didukung oleh Inggris, namun karena upayanya mengalami kegagalan, ia diasingkan ke Banda (Laan, 1939). 


\section{Penghapusan Kesultanan Banten}

Pada musim semi 1809, perlawanan baru juga muncul. Sultan yang mengikuti nasihat para Ulama, memberikan perlindungan kepada para pemimpin pejuang. Perlindungan politik tersebut membuat Daendels marah karena ia berharap Sultan berpihak pada Belanda dan menggunakan otoritasnya untuk menghentikan perlawanan terhadap Kolonial (Daendels, 1814). Setelah diputuskan bahwa Sultan tidak bisa "memulihkan perdamaian dan ketertiban" maka pada 7 Mei 1809 ia diturunkan karena tidak dapat dikendalikan Belanda. Ditunjuklah oleh Belanda Pangeran Aria Troena Laija serta Pangeran Sura Mangala sebagai pengganti pemerintahan. Model pemerintahan dalam bentuk Kesultanan kemudian direncanakan untuk dihapuskan karena membahayakan kepentingan Kolonial. Oleh karena itu, simbol Kesultanan dalam bentuk bentuk bangunan dihancurkan. Hal tersebut disayangkan, karena benteng dan bangunan historis dapat menjadi salah satu sumber belajar sejarah bagi generasi mendatang (Rosikin \& Hartono, 2016). Namun jika dipertahankan, simbol historis Kesultanan Banten berpotensi memunculkan perlawanan dan patriotisme rakyat Banten sehingga perlu dihapuskan.

Alasan paling utama yang melegitimasi Daendels untuk menghapuskan Kesultanan Banten yaitu karena dianggap mengadakan pemberontakan (Kartodirdjo, 1987). Tuduhan yang diberikan oleh Daendels kepada Kesultanan bahwa sistem pemerintahan tersebut melalui Sultan, masih menyukai serta melindungi para perampok dan para pembunuh sehingga penggabungan dengan Pemerintah Belanda tidak akan pernah dapat terlaksana (Daendels, 1814). Dalam berbagai catatan kolonial yang neerlando-sentris, banyak ditemukan stigmatisasi negatif terhadap kekuasaan tradisional sebagai penguasa yang melindungi perampok, pembunuh serta pemberontak. Setelah mendapatkan legitimasi, maka dimulailah implementasi politik untuk membuat kekuasaan tradisional menjadi lemah.

Gagasan tersebut diimplementasikan pada 22 Agustus 1810 dimana Banten dipecah dalam beberapa wilayah. Wilayah dataran rendah menjadi dua 'kabupaten' dikendalikan langsung oleh Belanda dan wilayah dataran tinggi untuk kebutuhan administrasi Sultan di Pandeglang (Bijdragen tot de taal-, land- en volkenkunde van Nederlandsch-Indië, 1867, 1867). Kemudian Sultan Muhamad Bien, yang digulingkan dan tempat tinggal Sultan terakhir ditempatkan di Batavia sebagai bentuk pengasingan. Menurut Daendels, pengasingan bagi Sultan dan pangeran yang melawan kolonial merupakan hukuman umum dan bahkan di Batavia terdapat kurang lebih 30 sultan dan pangeran yang akan diasingkan. Vlekke menuliskan bahwa, wilayah-wilayah pantai kesultanan dirampas sebagai wilayah yang diperintah langsung Batavia dan daerah pedalaman bertahan selama beberapa tahun sebagai negara bawahan Belanda (Vlekke, 2008). 


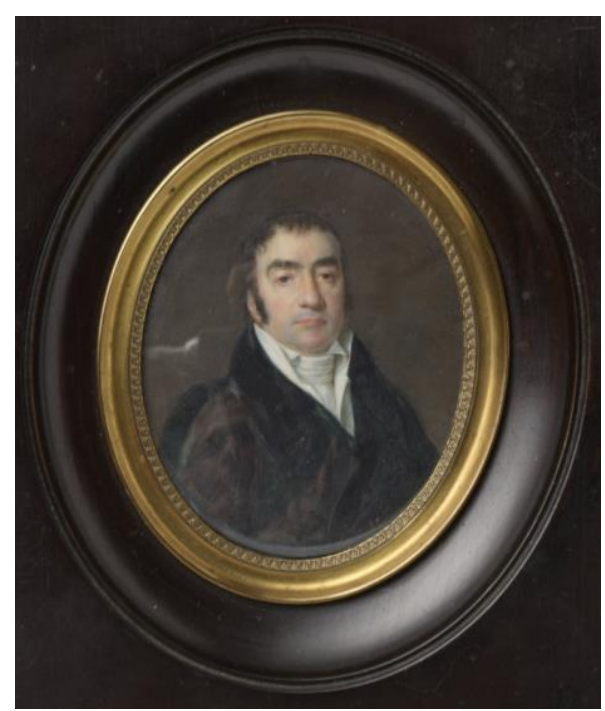

Gambar 7: Potret Daendels tahun 1815

(Portret van Herman Willem Daendels, Simon Jacques Rochard, 1815, Collectie Rijksmuseum)

Sebenarnya selain Kesultanan Banten, Daendels melakukan intervensi terhadap kekuasaan-kekuasaan lain di Jawa, diantaranya Cirebon (Kanoman dan Kasepuhan), Yogyakarta dan Surakarta (Vorstenlanden) (Marihandono, 2003). G. van Duinen mencatat bahwa Sultan Cirebon mengalami nasib yang sama dengan nasib Banten, begitupun para pangeran Surakarta dan Yogyakarta juga merasakan tinju besi Daendels. Bahkan ketika Sultan Yogya tidak menyukai Daendels, ia digulingkan dan diganti dengan sultan yang baru. Tahun 1810, Belanda dianeksasi dan diintegrasikan dalam Kekaisaran Perancis, tetapi kabar tersebut baru sampai di Jawa bulan Februari 1811. Bendera Perancis kemudian dikibarkan di Batavia karena Daendels adalah seorang pemimpin Jacobin dan pengagum berat Napoleon (Lombard, 2005a; Naval Intelligence Division, 1944). Sebagai pengagum revolusi Perancis yang sekuleristik, Daendels tentu merupakan anggota kelompok sekuler Freemasonry yang dilantik di loji Kampen "Le Profond Silence" (Stevens, 2004). Loji tersebut telah berdiri sejak tahun 1770 di Kampen, Provinsi Overijssel, Belanda (Louisa \& Stichting, 1871). Jawa kemudian menjadi koloni Perancis selama beberapa bulan dan kemudian Daendels dipanggil kembali oleh Napoleon. Ia digantikan Janssens menjadi Gubernur Jenderal Hindia Belanda. 


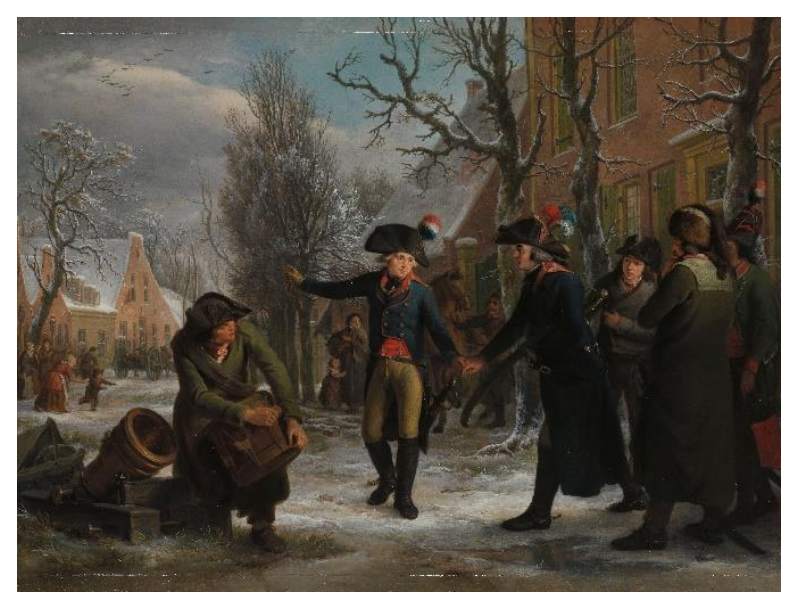

\section{Gambar 8: Daendels dengan seragam Perancis \\ (General Daendels Taking Leave of Lieutenant-Colonel Krayenhoff, karya Adriaan de Lelie dan Egbert van Drielst tahun 1795, Collectie Rijksmuseum)}

Pada tanggal 11 September 1811, pemerintah Inggris dinyatakan sebagai penguasa tertinggi di Jawa, melalui deklarasi yang ditandatangani oleh Earl of Minto, Gubernur Jenderal Benggala (Raffles, 1830). Pada tanggal 17 September 1811, semua kekuasaan Belanda di Hindia Timur secara de facto jatuh ke tangan Inggris Raya yang dalam beberapa tahun kemudian dikembalikan pada Belanda. Semenjak kekuasaan Inggris lepas, tanah dianggap sebagai bagian dari kedaulatan kerajaan sehingga tanah menjadi milik negara serta memunculkan eksploitasi yang lebih kuat (Maslahah \& Wahyu Hidayat, 2016). Namun perlawanan rakyat Banten tidak berhenti. Tegaknya kembali Kesultanan Banten setelah penghapusannya oleh Daendels secara rahasia dan turun temurun tetap menjadi harapan dari generasi selanjutnya. 80 tahun kemudian gerakan yang terkenal di Banten, tetap mencita-citakan gelar "raja Islam" yang dituntut sebagai hak oleh para pemimpin Gerakan Petani Banten 8 Juli 1888 (Lombard, 2005b). Tidak ketinggalan, Kesultanan Banten juga mewariskan transmisi budaya sekaligus islamisasi budaya yang masih mengakar di Banten sampai saat ini (Said, 2016).

\section{Kesimpulan}

Secara geopolitik, Banten merupakan kekuasaan pribumi terdekat dengan Batavia yang selama beberapa abad pernah membahayakan dan terus berpotensi menjadi musuh. Saat kekuasaannya melemah, Kesultanan Banten dihapuskan oleh Herman Willem Daendels melalui sebuah skenario politik. Sultan Banten dipaksa memenuhi persyaratan yang tidak mungkin dilakukan oleh seorang Sultan yaitu meninggalkan dan menyerahkan Keraton (istana) kepada Belanda. Terbunuhnya Du Puy (utusan Daendels) beserta para serdadunya, memberikan legitimasi bagi Daendels untuk menyerang dan mengepung Kesultanan Banten. Dengan persenjataan militer yang lebih canggih, pasukan Kesultanan dikalahkan dan 
akhirnya dikuasai. Kekalahan ini berimplikasi pada diturunkannya Sultan Banten serta diasingkan, harta milik istana pun dijarah, beberapa peninggalan Kesultanan dihancurkan, dan berakhir dengan penghapusan Kesultanan Banten. Penelitian ini memberikan gambaran historis tentang pentingnya kekuasaan politik dan militer untuk mencegah intervensi serta strategi politik asing. Bagi perkembangan pendidikan sejarah di Indonesia, penelitian ini dapat memberikan gambaran mengenai substansi materi yang berhubungan dengan konsep politik Imperialisme dan Kolonialisme Belanda, serta analisis terhadap sistem politik dan pemerintahan kerajaan Islam di Indonesia yang terdapat dalam kurikulum.

Penelitian ini memberikan latar belakang bagi berbagai peristiwa sejarah di Banten selanjutnya. Meskipun secara institusi politik Kesultanan sudah dihapuskan namun harapan kembalinya "Sultan Banten" tidak berhenti dan Islamisasi budaya tetap mengakar pada masyarakat Banten. Penelitian dapat dianalisis sebagai salah satu faktor historis munculnya pemberontakan petani Banten tahun 1888. Penelitian ini terbatas pada kajian pada tahuntahun terakhir kekuasaan Banten, diperlukan penelitian lainnya melalui penelusuran sumber-sumber lokal untuk memperkaya referensi penulisan sejarah Banten khususnya berkaitan dengan Kolonialisme dan Kesultanan Banten. Bagi pembelajaran sejarah, diharapkan penelitian ini dapat digunakan sebagai sumber belajar dalam pembahasan Kolonialisme Barat.

\section{Daftar Pustaka}

Ali, R. M. (2012). Pengantar Ilmu Sejarah Indonesia. Lkis Pelangi Aksara.

Bijdragen tot de taal-, land- en volkenkunde van Nederlandsch-Indië, 1867. (1867).

Carey, P. (2007). The Power of Prophecy: Prince Dipanagara and the End of an Old Order in Java, 1785-1855. (Vol. 249). Brill. http://www.jstor.org/stable/10.1163/j.ctvbqs55t

Daendels, H. W. (1814). Staat der Nederlandsche Oostindische bezittingen onder het bestuur van den gouverneur-generaal Herman Willem Daendels, ... in de jaren 1808-1811.

Daliman, A. (2012). Metode penelitian sejarah. Penerbit Ombak. https://books.google.co.id/books?id=wvsWnQAACAAJ

Djajadiningrat, H. (1983). Tinjauan Kritis tentang Sajarah Banten: Sumbangan bagi Pengenalan Sifat-Sifat Penulisan Sejarah Jawa. Penerbit Djambatan.

Duinen, G. van. (1918). Leerboekje voor de Lagere School in Indië (geïllustreerd).

Eijkman, A. J., \& Stapel, F. W. (1924). Leerboek der geschiedenis van Nederlandsch Oost-Indië.

Guillot, C. (2011). Banten: Sejarah dan Peradaban (Abad X - XVII). KPG (Kepustakaan Populer Gramedia).

Herlina, N. (2020). Metode Sejarah. Satya Historika.

Heusden, P. A. van. (1863). Handleiding tot de kennis der nieuwe geschiedenis, voor de kadetten van alle wapenen.

Kartodirdjo, S. (1987). Pengantar Sejarah Indonesia Baru, 1500-1900: Dari Emporium Sampai Imperium. Gramedia.

Kemp, P.H. van der. (1920). Sumatra in 1818. 
Kemp, Pieter Hendrik van der. (1915). De eerste publicatien over koloniale economie na Nederlands herstel in 1813.

Klerck, E. S. de. (1938). History of the Netherlands East Indies. W.L. \& J. Brusse.

Kuntowijoyo. (2003). Metodologi Sejarah. Tiara Wacana Yogya.

Laan, K. ter. (1939). Woordenboek van de vaderlandse geschiedenis met inbegrip van België, Oost- en West-Indië, Zuid-Afrika en de voormalige Nederlandse koloniën.

Lombard, D. (2005a). Nusa Jawa: Silang Budaya, Bagian I: Batas-Batas Pembaratan. Gramedia Pustaka Utama.

Lombard, D. (2005b). Nusa Jawa: Silang Budaya, Bagian III: Warisan Kerajaan-Kerajaan Konsentris. Gramedia Pustaka Utama.

Louisa, \& Stichting. (1871). Jaarboekje voor Nederlandsche vrijmetselaren, 1871, Deel: 5871, 1871. Gebroeders Giunta D’Albani.

Marihandono, D. (2011). Upaya Pemberantasan Korupsi di Hindia Timur. VOC: Pedagang Atau Penjajah.

Marihandono, D. (2003). Daendels dalam Naskah dan Cerita Rakyat: Cerita tentang Daendels di Pantai Utara Jawa. Seminar Internasional Tradisi Lisan IV, 25.

Maslahah, W., \& Wahyu Hidayat, A. (2016). Kehidupan Sosial-Ekonomi Masyarakat di Jawa 1830-1870. AGASTYA: JURNAL SEJARAH DAN PEMBELAJARANNYA, 6(02), 18-30. https://doi.org/10.25273/ajsp.v6i02.1454

Mulyana, A., \& Darmiasti. (2009). Historiografi Ddi Indonesia: Dari Magis-Religius hingga Strukturis. PT. Refika Aditama.

Naval Intelligence Division. (1944). Netherlands East Indies, Volume 2. Naval Intelligence Division.

Poesponegoro, M. D., \& Notosusanto, N. (2010). Sejarah Nasional Indonesia IV. Balai Pustaka.

Raffles, T. S. S. (1830). The History of Java. John Murray.

Ricklefs, M. C. (2005). Sejarah Indonesia Modern, 1200-2004. Serambi.

Ricklefs, M. C. (2008). Sejarah Indonesia Modern: 1200-2008. Serambi.

Rosikin, A., \& Hartono, Y. (2016). Museum Benteng Van Den Bosch (Benteng Pendem) Di Kelurahan Pelem Kecamatan Ngawi Kabupaten Ngawi (Latar Belakang Sejarah, Nilai, Dan Potensinya Sebagai Sumber Belajar). AGASTYA: JURNAL SEJARAH DAN PEMBELAJARANNYA, 6(02), 31-50. https://doi.org/10.25273/ajsp.v6i02.1039

Said, H. ahmad. (2016). Islam dan Budaya di Banten: Menelisik Tradisi Debus dan Maulid. Kalam: Jurnal Studi Agama Dan Pemikiran Islam, 10(109-138).

Sandick, R. A. van. (1893). Leed en lief uit Bantam, Tweede Druk. W. J. Thieme.

Sjamsuddin, H. (2012). Metodologi sejarah. Penerbit Ombak.

Staat der Nederlandsche Oostindische bezittengen, onder het bestuur van den gouverneurgeneraal Herm... / National Library of Australia. (n.d.). Retrieved December 21, 2020, from https://catalogue.nla.gov.au/Record/784378

Staat der Nederlandsche Oostindische Bezittingen, onder het bestuur van den GouverneurGeneraal Herman Willem Daendels (....) in de jaren 1808 - 1811, Hendrik van Teecklenburgh, 1814 - Rijksmuseum. (n.d.). Retrieved December 21, 2020, from https://www.rijksmuseum.nl/nl/collectie/NG-1976-6-A

Stevens, T. (2004). Tarekat Mason Bebas dan masyarakat di Hindia Belanda dan Indonesia, 1764-1962. Pustaka Sinar Harapan.

Sya, M., Marta, R. F., \& Marta, R. F. (2019). Tinjauan Historis Simbol Harmonisasi Antara Etnis Tionghoa dan Melayu di Bangka Belitung. Jurnal Sejarah Citra Lekha, 4(2), 153-168.

Tijdschrift voor Neerland's Indië jrg 2, 1864 (1e deel), no 1 Deel- 1e deel. (1864).

Universitas Gadjah Mada. (1958). Laporan Lengkap Atjara I dan II tentang Konsepsi Filsafat 
Sedjarah Nasional, dan Periodisasi Sedjarah Indonesia: Jogjakarta, 14 dan 15 Desember 1957. Universitas Gadjah Mada.

Velderhof, D. (1901). Overzicht van de geschiedenis onzer koloniën.

Verwey, A. (1905). De Beweging Algemeen Maandschrift Voor Letteren, Kunst, Wetenschap en Staatkunde, Derde Jaargang Vierde Deel. Uitgeven Door Maas \& van Suchtelen.

Vlekke, B. H. M. (2008). Nusantara: Sejarah Indonesia. Kepustakaan Populer Gramedia.

Warto. (2011). Kalang, Pesanggem, dan Sejarah Kaum Marjinal di Kawasan Hutan Rembang. Jurnal Sejarah Citra Lekha, XV(1), 33-41.

Wijono, R. S. (2017). Di Bawah Bayang-Bayang Ibukota: Penataan Daerah di Provinsi Banten dari Zaman Kolonial sampai Zaman Reformasi. Jurnal Sejarah Citra Lekha, 2(2), 126-142. 